\title{
Biomechanical properties of the spinal cord: implications for tissue engineering and clinical translation.
}

\author{
Richard D Bartlett ${ }^{1,2}$, David Choi ${ }^{\ddagger 2}$ \& James B Phillips $s^{*}, \neq, 1$ \\ ${ }^{1}$ Biomaterials and Tissue Engineering, UCL Eastman Dental Institute, University College London \\ ${ }^{2}$ Brain Repair \& Rehabilitation, Institute of Neurology, University College London
}

\section{${ }^{\ddagger}$ Authors contributed equally}

*Author for Correspondence:

Dr James B Phillips, Email: jb.phillips@ucl.ac.uk

Biomaterials \& Tissue Engineering

UCL Eastman Dental Institute,

256 Gray's Inn Road,

London,

WC1X 8LD.

Keywords: spinal cord; biomechanics; biomechanical properties; mechanical properties; central nervous system; spinal cord repair; spinal cord injury; tissue engineering; regenerative medicine

\section{Abstract (120 words):}

Spinal cord injury is a severely debilitating condition which can leave individuals paralysed and suffering from autonomic dysfunction. Regenerative medicine may offer a promising solution to this problem. Previous research has focused primarily on exploring the cellular and biological aspects of spinal cord, yet relatively little remains known about the biomechanical properties of spinal cord tissue. Given that a number of regenerative strategies aim to deliver cells and materials in the form of tissue engineered therapies, understanding the biomechanical properties of host spinal cord tissue is important. We review the relevant biomechanical properties of spinal cord tissue, and provide the baseline knowledge required to apply these important physical concepts to spinal cord tissue engineering. 


\section{Background:}

The spinal cord is a key component of the central nervous system (CNS), facilitating the transmission of sensory and motor information to and from the peripheral nervous system [1]. Like elsewhere in the CNS, the spinal cord is composed of both cellular and extracellular matrix components, and together these combine to form spinal cord [2]. The spinal itself is enclosed by the bony vertebral canal, and here it is enveloped by three meningeal layers (the dura, arachnoid, and pia) and bathed in cerebrospinal fluid (CSF) [3]. These surrounding structures offer some degree of structural protection, however, the spinal cord is still susceptible to injury.

Globally, spinal cord injury (SCl) affects between 250,000 to 500,000 new people each year [4]. SCI most commonly results from trauma to the cord, and the majority of cases are caused by high energy impacts such as road traffic collisions, falls, and contact sports. There are currently no effective treatments for $\mathrm{SCl}$, and individuals are often left with life-changing and catastrophic permanent injury [5]. Moreover, $\mathrm{SCl}$ is associated with a wide-range of medical co-morbidities [6] and the lifetime healthcare costs are considerable [7].

Regenerative therapies have long been thought to offer a solution to this problem, however, few have progressed through to clinical translation. A better understanding of cellular and molecular targets has driven a number of developments in tissue engineering and regenerative medicine [811], yet relatively little information is available about the biomechanical properties of spinal cord tissue in health, following trauma, or in patients with $\mathrm{SCl}$.

\section{The significance of biomechanics in tissue engineered therapies:}

The mechanical properties of the extracellular matrix (ECM) in endogenous or engineered tissue have the potential to significantly alter cell behaviour. For example, it is well-documented that alterations in the extracellular stiffness alone (the extent to which an object resists deformation) are sufficient to cause changes in fundamental cell behaviours such as differentiation, proliferation, and gene expression [12-14]. The mechanisms underlying this are complex, but positional changes in transmembrane receptors such as integrins and cadherins are thought to be key. Most likely, downstream signalling cascades such as focal adhesion kinase are activated. In turn, these cascades alter gene expression and cause changes to cell behaviour [15]. This is not a one-way exchange though, since cells also actively sense - and exert force on - their surrounding ECM environment [16, 17].

In the context of tissue engineered therapies, it is therefore important to design constructs with desirable mechanical characteristics in mind. Failure to do so is likely to hinder the cellular response, impede regeneration, and attenuate overall functional recovery [18]. In addition, mechanical mismatch between engineered tissue and the host tissue may be sufficient to cause additional implant-induced damage [19]. This review summarises the current data on the mechanical properties of spinal cord tissue, and relates these to novel opportunities in tissue engineering. For reference, some of the terms commonly used in deformation mechanics are summarised in Information Box 1.

\section{Methods of measuring the biomechanical properties of spinal cord tissue:}

The mechanical properties of a material or tissue can be measured in a number of ways. However, owing to the relatively soft nature of spinal cord tissue, only a small number of measurement techniques have been employed in practice. These have been used to measure the modulus values of spinal cord tissue. Modulus is a mechanical description of how a material deforms when external forces are applied, and (unlike stiffness) it is independent of the spatial dimensions of the sample being tested. Broadly speaking, the mechanical techniques used to measure spinal cord tissue can be 
divided into ex vivo and in-situ (live) methods. When considering the modulus values for spinal cord tissue, it is important to remember how variation in measurement technique will affect the end result.

\section{Ex vivo measurement techniques:}

Ex vivo measurement techniques have been used to compile the majority of the data pertaining to the mechanical properties of spinal cord tissue. Of these, uniaxial tensile testing has been the most commonly reported in the literature [20-27]. Tunturi et al. were perhaps one of the first groups to use this technique in the late 1970s [28]. They securely attached a section of canine spinal cord between two fixed points, and then applied a uniaxial tensional force parallel to the long-axis of the sample (see panel A, Figure 1)Figure 3. Diagrammatic overview of the main techniques used in the mechanical testing of CNS tissue.. The linear nature of this form of testing means that extension is easy to quantify, and, when deformation is in the elastic phase, modulus calculation relatively straightforward. Nevertheless, securely fastening soft and often small pieces of spinal cord tissue to each end of a testing jig can be challenging. The technique has been used to measure a number of mechanical properties, including: stiffness, modulus and stress. These factors, in addition to the high prevalence of tensional testing rigs across biomaterials laboratories, go some way to explaining why this technique has been so widely used.

Compression testing has also been used. This can either be performed by the gross uniaxial compression testing of whole specimens [29-32], or by material surface indentation with atomic force microscopy (AFM) [33, 34]. Similar to tensile testing, uniaxial compression offers a simple experimental setup and relatively straightforward analysis of the bulk material properties. To this end, uniaxial compression testing provides the same mechanical information as uniaxial tensile testing, but may negate some of problems associated with tensile specimen attachment. AFM is less useful at characterising bulk material properties, but is an excellent technique for mapping the subtle topographical changes across the surface of a material down to the cellular level. This is most commonly achieved through using a spherical indenter (in the order of $10-20 \mu \mathrm{m}$ ) mounted to a piezoelectric micro-cantilever which probes the surface [35]; forces in the range of piconewtons (pN) are then applied. As the tip scans the surface, a laser is used to measure the displacement of the cantilever [36]. Given that the magnitude of force applied through the cantilever is known, tip displacement can be measured (using the laser), and extrapolated to determine the material - or tissue - surface properties [37]. AFM is advantageous in being able to detect nanoscale changes on the surface, and this may not only be useful for discerning differences between grey and white matter, but also for mapping micro-architectural mechanical heterogeneity across spinal cord crosssections [34]. This level of spatial resolution is an unrivalled advantage of AFM, yet it also means the technique is less suitable for characterising bulk mechanical properties of specimens. Similar to other techniques, AFM also suffers from being unable to characterise the internal mechanical properties of intact tissue.

Ozawa et al. have also trialled the use of pipette aspiration to apply a suction force to transversely sectioned spinal cord tissue [38]. Forces created by the presence of a vacuum then pull a small bolus of tissue into the pipette end. Given that the magnitude of suction force being applied to the specimen is known, measuring the volume of tissue displaced with a high-frequency video camera allows a modulus value to be determined (see panel $\mathrm{D}$, Figure 2). This technique is relatively novel, yet it has proved useful in discerning the potential differences which may exist between the mechanical properties of grey and white matter in rabbit spinal cord.

Considerations for accuracy in the ex vivo measurement of spinal cord tissue modulus: 
Owing to the soft viscoelastic nature of spinal cord tissue, there are a number of challenges to obtaining accurate measurement values of modulus and stiffness. The causes of variation are likely to be two-fold: intrinsic differences in the parameters of cord tissue itself, and variations in external measurement parameters.

Pre-conditioning is one potential source of external variation. This technique has been used by a number of groups and it involves the cyclical straining of samples by small amounts prior to the final measurement [39]. The concept of pre-conditioning is not new [40], and it is hypothesised that the technique causes fluid redistribution within each specimen to standardise inter-sample variability [41]. Nevertheless, empirical work has shown that for spinal cord tissue, the number of preconditioning cycles performed has the potential to confound and influence end modulus measurements [25, 42]. Whilst it is generally accepted that pre-conditioning is an aid to reducing inter-sample variability, a standardised protocol of how to perform it remains controversial. Bilston et al. recommend that pre-conditioning parameters should always be reported alongside main experimental results, and also that the strain values used in pre-conditioning should be equivalent to the highest anticipated values required as part of the study [42]. Even so, the total number of preconditioning cycles which should be performed is disputed. Some groups suggest that $6-7$ cycles may be sufficient to allow for mechanical standardisation between samples [43], whilst others recommended that in excess of 15 cycles must be performed to guarantee consistency [25]. The high water content of native spinal cord tissue makes inter-sample variability high; however, a quest to reduce inter-sample variability must not come at the cost of artificially manipulating tissue to an extent where it deviates from its original characteristics. For example, in the case of other anisotropic tissues such as ligament, extensive pre-conditioning has been shown to alter collagen fibre alignment [44]. As such, researchers must be aware that pre-conditioning may change tissue architecture and confound end results [45].

Ambient conditions such as temperature, prior to, and at the point of measurement, have been shown to significantly alter the mechanical properties of porcine CNS (brain) tissue [46]. Given that a number of studies fail to sufficiently report storage and testing temperatures, valid comparison of results between research groups is challenging. Similarly, humidity may also affect the results gathered from mechanical testing, and it too has been an underreported methodological consideration. As such, it has been encouraging where groups haven given explicit details of their experimental setup and testing parameters. Where methods have been reported, most commonly, samples have been submerged in isotonic saline [22, 24, 47] or artificial cerebrospinal fluid [33, 34].

Other external factors, such as the time delay post mortem before mechanical testing occurs must also be considered. Data from Oakland et al. suggest that tangent modulus, as defined by the gradient of a stress-strain curve at a set strain, may increase as a function of time. This would suggest that tissue stiffness increases with time after death [25]. This has important implications, particularly where spinal cord tissue is stored for extended periods prior to mechanical testing, where the effect of different storage conditions and temperatures remain unknown. One would expect that the use of tissue preservation fluid may ameliorate such deterioration, yet the mechanical changes that occur within spinal cord tissue post-mortem remain fundamentally unexplored.

How specimens are attached to testing apparatus may also affect the results of mechanical testing. For uniaxial tensile testing, the majority of groups have advocated the use of cyanoacrylate adhesives ('superglue') to attach cord tissue to testing jigs [22, 27, 48, 49], while others have favoured clamping [47] or suture attachment [24]. It remains poorly characterised how different attachment methods may influence mechanical measurement, yet in the context of uniaxial tensile 
testing specifically, measuring only the central portion of the taught specimen - known as 'necking' may be sufficient to negate some of these differences [27]. Likewise, for compression testing, whether specimens should be attached at all remains to be explored. In the case of indentation testing, friction may also significantly influence results, and in early phase measurements it has been hypothesised to be the dominant force between the indentation probe and the specimen [39]. In the case of AFM, sharpness of the probe tip may contribute to measurement inconsistency, where changes in cross-sectional area may occur over time as the tip becomes blunter with repeated use [50]. Some studies have also indicated that the properties of live and dead spinal cord tissue may be significantly different [51], and that discrepancies between human and animal cord could exist [52].

\section{Non-invasive measurement techniques used to measure spinal cord tissue in-situ:}

In-situ measurement of mechanical properties of the spinal cord have been performed using magnetic resonance elastography (MRE). MRE has previously been used to measure the mechanical properties of other tissue types including liver, spleen, kidney, pancreas, prostate, vasculature, bone and muscle [53], yet its application in measuring the stiffness of the central nervous system is relatively new. MRE generates and propagates shear waves through tissue, before then acquiring a set of serial MR images. These are digitally processed and used to generate a quantitative 3dimensional tissue stiffness map [54]. The technique is safe for human use [55, 56], and it is now being increasingly used clinically in the non-research setting as a validation tool for mapping mechanical changes in liver fibrosis [57]. The mechanical properties of the brain have already been explored using MRE [58-62], however, the technique is yet to be applied to measure spinal cord tissue specifically [63].

MRE negates a number of the problems associated with ex vivo measurement of spinal cord tissue, but it is not without its flaws. Fundamentally, owing to the very nature of the technique, MRE can only be used to apply shear forces. As such, only shear moduli have been calculated [53]. Moreover, variations in the computational modelling and analysis techniques may alter the resulting tissue stiffness that is calculated. Additionally, although a small number of heterogeneous rheometerbased studies have reported the shear moduli of brain tissue ex vivo [64-66], there is currently no experimental data to benchmark the shear moduli results generated by MRE with those that have been generated through more established laboratory techniques. Nevertheless, in terms of measuring the mechanical properties of spinal cord tissue for informing tissue engineering applications, MRE may be an invaluable tool. Specifically, it allows for the mechanical characterisation of spinal cord tissue in a physiological environment, and it negates several of the challenges associated with accurate ex vivo measurement. Equally, MRE may one day be used for personalised 'biomechanical matching', where the mechanical properties of tissue engineered constructs might be matched in a bespoke fashion to those measured by MRE in individual patients.

\section{Current understanding of the mechanical properties of spinal cord tissue:}

Given the difficulties in ascertaining reliable and reproducible data, it is unsurprising that the mechanical properties of spinal cord tissue have remained variable. Despite this, a number of concordant observations have been made between multiple groups, and these suggest there are likely to be some fundamentally replicable principles. Firstly, like a number of other soft tissues [67], spinal cord tissue has been shown to display viscoelastic properties $[20,22,29]$. This means that under deformation it exhibits a combination of both viscous (fluid) and elastic (solid) behaviours [68]. Consequently, it is not possible to model spinal cord tissue using a classic linear deformation relationship. Instead, complex hyperelastic models - of which, perhaps the Ogden model is the most 
well-known - must be used [69]. These utilise finite element analysis, and break down complex mathematical relationships into simpler, more discrete aspects which can be modelled [70].

Viscoelasticity has a number of important connotations in the spinal cord. Firstly, and perhaps most importantly, it means that any modulus value calculated for spinal cord tissue is only true for a specific given strain value. Modulus (or stiffness) is an inherent function of the stress-strain relationship in viscoelastic materials (see red tangent lines in Figure 2), and thus quoted modulus values will change as different amounts of strain are applied [25]. Ultimately, this means that spinal cord tissue does not have a single modulus value, but rather a range of values which are strain dependant. This has important implications in terms of data replicability, since unless authors explicitly state the strain values which they have used to calculate modulus the results become largely discordant [39]. To complicate matters, the stresses recorded in spinal cord tissue not only vary with absolute strain, but also with strain-rate (Figure 3) [20, 22]. This means that strain-rates must also be carefully reported to allow for cross-experimental comparison.

Stress-relaxation behaviour is also an inherent property of spinal cord tissue (Figure 4). This phenomenon is typical of viscoelastic materials, and refers to how internal stresses within a material (under a constant strain) decrease exponentially over time [71]. This is significant in terms of modelling, since a so-called 'relaxation modulus' must be incorporated into computational models to improve precision and predictive accuracy $[72,73]$. Pragmatically, the phenomenon of stressrelaxation is also important for tissue engineering, since the measured mechanical properties of a biomaterial may vary over time - particularly after handling, for instance. The precise stressrelaxation time of spinal cord tissue is difficult to quantify, mainly owing to variations in experimental setup. However, current data suggests that spinal cord tissue may take anywhere in the region of 25 seconds to 30 minutes to fully equilibrate and come to rest after a loading force has been applied [39]. Certainly, the timescale and magnitude of this phenomenon would be worthy of further exploration, since stress-relaxation behaviours may confound the determination of modulus in a number of experimental setups.

Anatomical features are also likely to contribute to the intrinsic mechanical properties of the spinal cord. A number of studies have demonstrated that there may be mechanical differences between grey and white matter in the CNS for instance (Table 1). Currently, although differences between the two tissue types have been observed, there is no clear consensus as to which is stiffer. Some studies have suggested that grey matter has a higher modulus (and thus is stiffer), as measured by AFM, pipette aspiration, and MRE, respectively $[33,38,58]$, whilst others using indentation and MRE have implied the opposite [74-77]. Other groups have indicated that there may be no differences at all between the two tissues $[78,79]$.

Reasons underlying this disparity are difficult to ascertain. However, one explanation may be that the direction of force applied has an effect on stiffness. White matter is known to be highly anisotropic due to the organised tracts which run within it [80-82], and thus the direction in which strain is applied may have the potential to alter modulus. Feng et al. suggest that anisotropy in the spinal cord may affect shear modulus by as much as 30-50\% [78], whilst results by Koser et al. indicate that differences between grey and white matter are likely to be independent of the direction of the force applied [34] . Moreover, one study has used MRE to demonstrate regional variations in tissue stiffness throughout the brain, and this may explain some of the discordance in grey and white matter measurements between different research groups [83]. In terms of why such differences may exist, there is no clear consensus. Shreiber et al. have used selective glial disruption 
in developing chick embryos to investigate the differences which may exist between the two tissue sub-types, and they suggest that the mechanical differences are unlikely to be due to differences in myelin abundance. Rather, they indicate that they may be due to poorly understood architectural interactions between neurons and glia, specifically axons and oligodendrocytes [26].

Given the disparity of modulus values generally, and the measurement limitations already mentioned, it is difficult to draw meaningful conclusions about the absolute values of grey and white matter modulus in spinal cord tissue. Nevertheless, in terms of tissue engineering applications these disparities may be unimportant. It is true that there is considerable variability in the modulus values measured between studies, yet the difference between grey and white matter of the same studies is relatively small. This suggests that, other factors aside, providing tissue engineered constructs match the mechanical properties of the spinal cord as a whole, they are likely to be suitable for use in constructing either tissue sub-type. Data from Ichihara et al. support this sentiment, suggesting that for low strains there is very little difference in the deformation characteristics between grey and white matter during tensile testing [23] - displayed Figure 5. Similarly, Feng et al. have shown that the storage moduli of grey and white matter do not differ significantly until higher frequencies (proxy for increased strain-rates) are tested during MRE [78] - summary data displayed Table 1. Similar mechanical properties between grey and white matter could be logical from an evolutionary perspective too, since considerable mechanical mismatch between the two tissue sub-types in the adult CNS might increase the chance of harmful shear forces being generated, and potentially lead to damage in vivo [84]. Nevertheless, the evidence is inconclusive, and a review by Kuhl et al. suggests that mechanical mismatch may actually be necessary for the successful development of the CNS in the embryo [85].

In addition to grey and white matter regions, other physiological variables may also affect the mechanical properties of spinal cord tissue. Namely, although not for the spinal cord specifically, data from Weavee et al. have suggested that perfusion pressure may have a dramatic effect on the shear modulus of biological tissues generally - Figure 6 . Their results suggest that shear modulus may vary by as much as $0.1-0.3 \mathrm{kPa} / \mathrm{mmHg}$ [86]. And, given that spinal cord perfusion pressure is normally in the region of $50-140 \mathrm{mmHg}[87,88]$, this means that there may be large discrepancies ( $5-42 \mathrm{kPa}$ ) in modulus values between perfused (live) and non-perfused (dead) tissue. This may introduce systematic discrepancies between the results of ex vivo and in-situ measurement techniques.

Physiological strain may also help explain some of the differences between in-situ and ex vivo measurements. Ichihara et al. suggest that in a bovine model the in-situ strain on the cord may be as high as $5 \%$ [23]. As discussed, given that initial loading strain is believed to increase the stiffness of viscoelastic tissues (recall Figure 4) [22], this may have important connotations for the modulus values reported. Similarly, data gathered from the lamprey eel suggest that strain could increase to levels as high as $15 \%$ during periods of physical activity [24], thus giving rise to the possibility of differences in modulus between active and resting animals.

Biological maturity is also likely to contribute to spinal cord tissue stiffness. Little data exists for agerelated changes in the CNS specifically, however, modulus changes with age have been welldocumented in other tissues such as bone [89] and muscle [90, 91]. One study by Arani et al. has attempted to use MRE to probe the effect of age on the mechanical properties of the human brain. Their results were inconclusive: they found a mild inverse linear correlation between age and stiffness in the cerebrum, yet no such differences in the cerebellum [83]. In contrast, data from Elkin et al. suggests that, in rats at least, CNS stiffness is likely to increase during adolescence [92]. Clarke et al. also report that stress-relaxation behaviour in spinal cord tissue between adult and neonate 
rats differs significantly, and they consequently speculate that such differences may explain the increased severity of SCls typically seen in children [21]. Albeit not conclusive, collectively these results imply that CNS tissue stiffness is likely to increase through life; this will be an important consideration in the fabrication of personalised tissue engineered therapies.

Minimal data currently exists as to whether rostro-caudal location within the cord has any influence on modulus, however, data by Fiford et al. suggest that anatomical location may influence local tissue stiffness in the rat [22] - see Figure 7Figure . If this is true, then it has important connotation for mechanical measurement, since - depending on the section of cord which is sampled for testing the mechanical properties would be expected to differ. Currently, very few studies report results for testing more than one anatomical region of the cord. Similarly, different research groups use different animal species, and this must be remembered as a key consideration in explaining the variability between studies (Table 1) [38, 74, 75, 77, 78, 93, 94].

\section{Future perspectives:}

It is clear from the literature that a complete understanding of the biomechanical properties of spinal cord tissue is currently lacking. This is due to a number of measurement difficulties, including strain-rate dependence, stress-relaxation behaviour, and variability in experimental testing conditions. Combined, these make the accurate mechanical characterisation of this soft, viscoelastic tissue extremely challenging. Future work must build-on the successes of previous research, and continue to develop our understanding of this clinically pertinent field.

Owing to the difficulties associated with accurately measuring spinal cord tissue, future research must aspire to promote absolute methodological transparency. It remains unknown whether a number of variables such as temperature, humidity and time post-mortem affect tissue stiffness, and so it is important that these factors are routinely reported to allow for more easy comparison between experimental setups. Moreover, given the confounding effects of pre-conditioning and strain-rate on final modulus value, it is important that these are also reported routinely. In fact, better understanding how these variables affect the mechanical properties of spinal cord tissue would merit investigation in its own right, given that conclusive results would greatly benefit the field as a whole.

Future work should also aim to make data analysis techniques as transparent as possible too. Currently there are disparities in how modulus values are calculated, and given that spinal cord does not obey linear deformation characteristics, it is paramount that stress and strain values are reported alongside modulus values. Put simply, unless the rate and magnitude of strain are clearly stated with modulus values, then the results become largely meaningless. This is particularly true where tangent modulus (Figure 2) has been calculated for ex vivo experiments, and where complex computational models have been used in MRE. Alternatively, where this is not appropriate, authors may wish to report the range of modulus values they have observed over their testing parameters.

For tissue engineering applications, it is also important that future experiments focus on exploring stiffness at low strains in particular. To date, a number of experiments have determined modulus at high strain values, and although these are likely to be useful in creating computational injury models, they are likely to be less useful in the context of tissue engineering. Specifically, it is unlikely that such strains would be encountered by spinal cord tissue during non-pathological activity, and so future work should aim to map the mechanical properties of cord tissue at rest and during normal physiological movement. Historically, accurate measurement has been difficult owing to the delicate nature of extracted spinal cord tissue, however, in-situ measurement techniques such as MRE offer exciting new possibilities. Although this technique is highly effective at characterising perfused in- 
situ spinal cord tissue, in the context of tissue engineering, and for the high-throughput benchmarking of novel (unperfused) biomaterials, new ex vivo protocols may also need to be developed. Furthermore, although the spatial resolution of MRE is in the order of $2 \mathrm{~mm}$ [95], the temporal resolution of MR-based techniques is generally poor [96]. This may limit the future use of MRE in mapping mechanical differences between resting and movement states. In addition, although in-situ MRE imaging is able to overcome a number of limitations associated with ex vivo measurement, it is currently unable to match the spatial resolution of ex vivo techniques such as AFM.

One ex vivo technique which researchers may wish to explore further is dynamic mechanical analysis (DMA). This is an automated technique which uses sinusoidal compression or tension to map the mechanical properties of soft viscoelastic materials over a range of strains and frequencies. It also alows for the calculation of storage moduli, loss moduli, and compound moduli through the measurement of phase-lag relative to the original compressive or tensional movement. Testing parameters such as temperature may also be tighly regulated on some specific machines [97], and thus it negates some of the discussed measurement consistency problems. Importantly, DMA also allows for the precise control of strain over a range of values, and a number of frequencies can be easily tested on single tissue samples. Thus, it allows for the accurate characterisation of viscoelastic tissues over a range of strain-rates and facilitates more accurate modelling of the curvilinear viscoelastic behaviour. To date, only one paper cites a primitive version of the technique to measure spinal cord tissue [98], however, others have successfully used DMA to measure mechanical properties in the context of peripheral nerve tissue conduits [99] and interfacial electrode polymers [100]. In the context of tissue engineering, DMA may offer a reliable method to benchmark newly synthesised biomaterials against endogenous spinal cord tissue.

Although experimental data are highly variable, we can be assured that native spinal cord tissue is both soft and viscoelastic - recall Table $\mathbf{1}$ for specific details. This limited information may be insufficient to create accurate computational injury models for SCI [101,102], yet it provides vital information about modifiable design features for tissue engineered constructs. Presumably, these will aim to mimic the biomechanical properties of endogenous cord tissue, and so low stiffness and viscoelasticity are likely to be key parameters in selecting appropriate candidate biomaterials. Despite this, the ideal mechanical properties of therapeutic constructs remain largely unknown. After all, although the mechanical properties of a pro-neurogenic construct are likely to be similar to endogenous spinal cord tissue, they may not be identical. As we have already discussed, the mechanical properties of the developing (and pro-regenerative) CNS may be significantly different from those of the adult. The stiffness of the CNS has been shown to increase through adolescence [103] - in the rat brain at least - and it is feasible that spinal cord tissue may be softer still during early embryonic development. Moreover, at the cellular level, neurite outgrowth ex vivo has been shown to be highest on ultra-soft substrates [67, 104]. Specifically, substrates of shear modulus 150 Pa have been shown to be the most permissive for neuron growth, and stiffer substrates close to 1 $\mathrm{kPa}$ have been shown to incrementally activate the astrocyte population [105]. One should be aware that both these modulus values are considerably softer than a number of currently reported modulus results (Table 1). As such, manipulating the mechanical properties of tissue engineered scaffolds may offer exciting new therapeutic prospects. For example, future work may explore the effects of tuning mechanical properties on individual cell populations. In doing so, it may be possible to selectively activate the neuronal cell population, whilst concomitantly suppressing astrocyte reactivity. This is likely to be important in acute phase therapies, where selective mechanical suppression of the glial population could reduce secondary inflammation and minimise long-term injury [106]. 
Exploring whether mechanical differences exist rostro-caudally along the cord would also warrant further investigation. A number of animal studies use the thoracic or lumbar cord for mechanical testing [21], yet the majority of human injuries occur in the cervical region [107]. If rostro-caudal discrepancies do exist then this may have important connotations for the design of tissue engineered therapies, where the mechanical properties of constructs may be required to differ with anatomical location. In addition, it may be interesting to investigate the temporal mechanical changes which occur following traumatic injury. For example, whilst it is generally assumed that gliotic scar tissue is stiffer than healthy tissue [108], by how much, and when this mechanical change occurs, remains poorly quantified. Given that different tissue engineered delivery mechanisms (e.g. injectable self-assembling peptides vs. structured scaffolds with architecture) are likely to be delivered at different times post-injury [109], a more precise understanding of the patho-mechanical changes that occur would be useful [110].

The efficacy of tissue engineered therapies in repair of the human spinal cord remains uncertain. What is clear, however, is the undoubted significance the extracellular mechanical environment in orchestrating a permissive cell response. Even so, it must be remembered that - in addition to being efficacious - tissue engineered constructs must also be clinically viable. Ultimately, all proneurogenic scaffolds must eventually be scalable and comply with good manufacturing practice (GMP). Failure to do so will mean that even the most promising therapies will not be approved by regulatory health bodies (such as the FDA), and as such they will not be usable in the clinical setting [111]. Similarly, handling properties must also not be neglected. For example, constructs which are too soft are unlikely to be tenable to use during a surgical procedure, and such they will not be incorporated into wide-spread clinical practice. Moving forward, it is important to remember that no single measurement technique is likely to have the power to address all of these pertinent research questions, and researchers will need to carefully consider the advantages and disadvantages of each technique to fit the specific aim of the research (Figure 8). For example, AFM may be particularly useful in mapping the micro-architectural mechanical differences over crosssections prepared from spinal cord tissue, whilst MRE may be more suitable for pragmatically measuring perfused human cord in-situ.

Overall, a great deal of progress has been made in mapping the complex viscoelastic behaviours of spinal cord tissue. In the context of advancing regenerative medicine approaches, future experiments should not only continue to answer fundamental questions about the biomechanical properties of spinal cord tissue, but should also aim to address those questions that are most relevant to tissue engineering. This will increase our opportunity to capitalise on the exciting new therapeutic prospects offered by mechanical manipulation, and hopefully provide a stronger platform for tissue engineering to improve outcomes following spinal cord injury in the future.

\section{Executive summary:}

\section{Background:}

- Spinal cord injury is a life-changing and debilitating condition for which there are currently no established clinical therapies.

- Tissue engineering may offer a way to encourage regeneration and repair at the cellular level, and to improve functional recovery after injury.

- The mechanical properties of tissue have the potential to alter cell behaviour. This is an important consideration when developing tissue engineered constructs. 
- Measuring the mechanical properties of spinal cord tissue: Spinal cord tissue has been measured using a range of ex vivo and in-situ techniques, and it has been found to display viscoelastic biomechanical properties, similar to other soft biological tissues

- The viscoelastic nature of spinal cord tissue make it difficult to accurately characterise, whereby factors such as strain-rate and stress-relaxation behaviours often confound mechanical measurement.

- The structural properties of spinal cord tissue may be affected by a range of factors, including sub-tissue type, physiological strain, perfusion pressure and anatomical location.

\section{Conclusions \& future work:}

- Future work must concentrate on ensuring consistency in measurement techniques, and explore the role of mechanical properties in creating a permissive repair environment.

- Practical considerations such as scalability, surgeon desirability, and good manufacturing practice must be also considered in the design of future, clinically tractable therapies.

\section{Financial disclosure/Acknowledgements:}

We would gratefully like to acknowledge Richard Hall, Professor of Spinal Biomechanics at the University of Leeds, for his helpful comments during preparation of this manuscript. This work was kindly funded by the UCL MBPhD Programme and the Sackler Foundation. No other competing financial interests to be declared. 


\section{Associated figures \& tables:}

Stress - Force per unit area. Generated by the reactive internal forces within a body when an external load is applied. Measured in in $\mathrm{N} / \mathrm{m}^{2}$, also known as the pascal $(\mathrm{Pa})$.

Strain - The response of a system to an applied stress. Quantified by the deformation of a material relative to its initial reference size. Measured as a ratio or percentage of new length relative to original length; does not have units.

Shear - The component of stress generated when a force is applied parallel, rather than perpendicular, to the crosssection of the material. Measured in pascal $(\mathrm{Pa})$.

Stiffness - The extent to which an object can resist deformation in response to an applied force. A property specific to the structure of a body rather than its materials composition. The opposite of flexibility. Measured in N/m.

Modulus - The tendency of a material to deform along an axis when opposing forces are applied along that axis. A constant for each material. Can be in the form of bulk, shear, or Young's moduli. All forms measured in pascal.

Elastic deformation - The reversible and linear phase of deformation. Materials in this phase of deformation will spontaneously return to their original shape once external deformation forces have been removed. Transition to plastic deformation phase once yield point has been reached (defined below).

Plastic deformation - The irreversible and non-linear phase of deformation. Materials in this phase of deformation will not spontaneously return to their original shape once external deformation forces are removed.

Yield point - The stress at which material deformation switches from elastic deformation to plastic deformation. Measured in pascal $(\mathrm{Pa})$.

Viscoelasticity - The term used to describe materials which display both viscous (fluid) and elastic deformation characteristics. A combination of these properties means that viscoelastic materials exhibit time-dependent strain behaviours. Classically, this means that the measured stiffness of a viscoelastic material is dependent on rate at which the force is applied.

Information Box 1. Summary of some of the key mechanical terms used in deformation mechanics and mechanical testing. 


\begin{tabular}{|c|c|c|c|c|}
\hline Study & Model & Methodology & $\begin{array}{c}\text { Grey matter modulus } \\
(\mathrm{kPa})\end{array}$ & $\begin{array}{l}\text { White matter modulus } \\
(\mathrm{kPa})\end{array}$ \\
\hline $\begin{array}{c}\text { Ozawa et al. } 2001 \\
\text { [38] }\end{array}$ & Ex vivo & $\begin{array}{l}\text { Pipette } \\
\text { aspiration of } \\
\text { rabbit SC }\end{array}$ & $\begin{array}{c}\text { Axial: } 3.40 \pm 1.4 \\
\text { Frontal: } 3.0 \pm 0.3 \\
\text { Sagittal: } 3.5 \pm 0.9\end{array}$ & $\begin{array}{c}\text { Axial: } 3.40 \pm 0.9 \\
\text { Frontal: } 3.5 \pm 0.5 \\
\text { Sagittal: } 2.8 \pm 0.4\end{array}$ \\
\hline $\begin{array}{c}\text { Christ et al. } 2010 \\
\text { [93] }\end{array}$ & Ex vivo & $\begin{array}{c}\text { AFM } \\
\text { indentation } \\
\text { of adult rat } \\
\text { cerebrum }\end{array}$ & $0.45 \pm 0.053$ & $0.29 \pm 0.074$ \\
\hline $\begin{array}{l}\text { Budday et al. } \\
2015 \text { [74] }\end{array}$ & Ex vivo & $\begin{array}{c}\text { Indentation } \\
\text { of bovine } \\
\text { brain }\end{array}$ & $1.40 \pm 0.29$ & $1.90 \pm 0.59$ \\
\hline $\begin{array}{c}\text { Koser et al. } 2015 \\
\text { [34] }\end{array}$ & Ex vivo & $\begin{array}{c}\text { AFM } \\
\text { indentation } \\
\text { of mouse } \\
\text { spinal cord } \\
\end{array}$ & $\begin{array}{c}\text { Coronal: } 0.128^{*} \\
\text { Sagittal: } 0.127^{*} \\
\text { Transverse: } 0.125^{*}\end{array}$ & $\begin{array}{c}\text { Coronal: } 0.075^{*} \\
\text { Sagittal: } 0.077^{*} \\
\text { Transverse: } 0.048^{*}\end{array}$ \\
\hline $\begin{array}{c}\text { Green et al. } 2008 \\
{[94]}\end{array}$ & In-situ & $\begin{array}{c}\text { MRE of } \\
\text { human brain }\end{array}$ & $3.10 \pm 0.10$ & $2.70 \pm 0.10$ \\
\hline $\begin{array}{c}\text { Feng et al. } 2013 \\
{[78]}\end{array}$ & In-situ & $\begin{array}{l}\text { MRE of ferret } \\
\text { brain }\end{array}$ & $\begin{array}{r}400 \mathrm{~Hz}: 3.07 \pm 0.28 \\
600 \mathrm{~Hz}: 5.20 \pm 0.26 \\
800 \mathrm{~Hz}: 7.31 \pm 0.20\end{array}$ & $\begin{array}{l}400 \mathrm{~Hz}: 3.14 \pm 0.27 \\
600 \mathrm{~Hz}: 5.30 \pm 0.36 \\
800 \mathrm{~Hz}: 6.88 \pm 0.47\end{array}$ \\
\hline $\begin{array}{c}\text { McCracken et al. } \\
2005 \text { [75] }\end{array}$ & In-situ & $\begin{array}{c}\text { MRE of } \\
\text { human brain }\end{array}$ & $7.5 \pm 1.6$ & $11.6 \pm 2.4$ \\
\hline $\begin{array}{r}\text { Uffmann et al. } \\
2004 \text { [76] }\end{array}$ & In-situ & $\begin{array}{c}\text { MRE of } \\
\text { human brain }\end{array}$ & $12.90 \pm 0.90$ & $15.20 \pm 1.4$ \\
\hline $\begin{array}{c}\text { Zhang et al. } 2011 \\
\text { [77] }\end{array}$ & In-situ & $\begin{array}{c}\text { MRE of } \\
\text { human brain }\end{array}$ & $\begin{array}{l}\text { Cerebrum: } 2.34 \pm 0.22 \\
\text { Cerebellum: } 1.77 \pm 0.24\end{array}$ & $\begin{array}{l}\text { Cerebrum: } 2.41 \pm 0.23 \\
\text { Cerebellum: } 1.85 \pm 0.18\end{array}$ \\
\hline
\end{tabular}

Table 1. A summary of studies which have compared the moduli of grey and white matter in the central nervous system. Tabulated data depicts the mean modulus value reported by research group \pm SD (where available). * Indicate median values. 


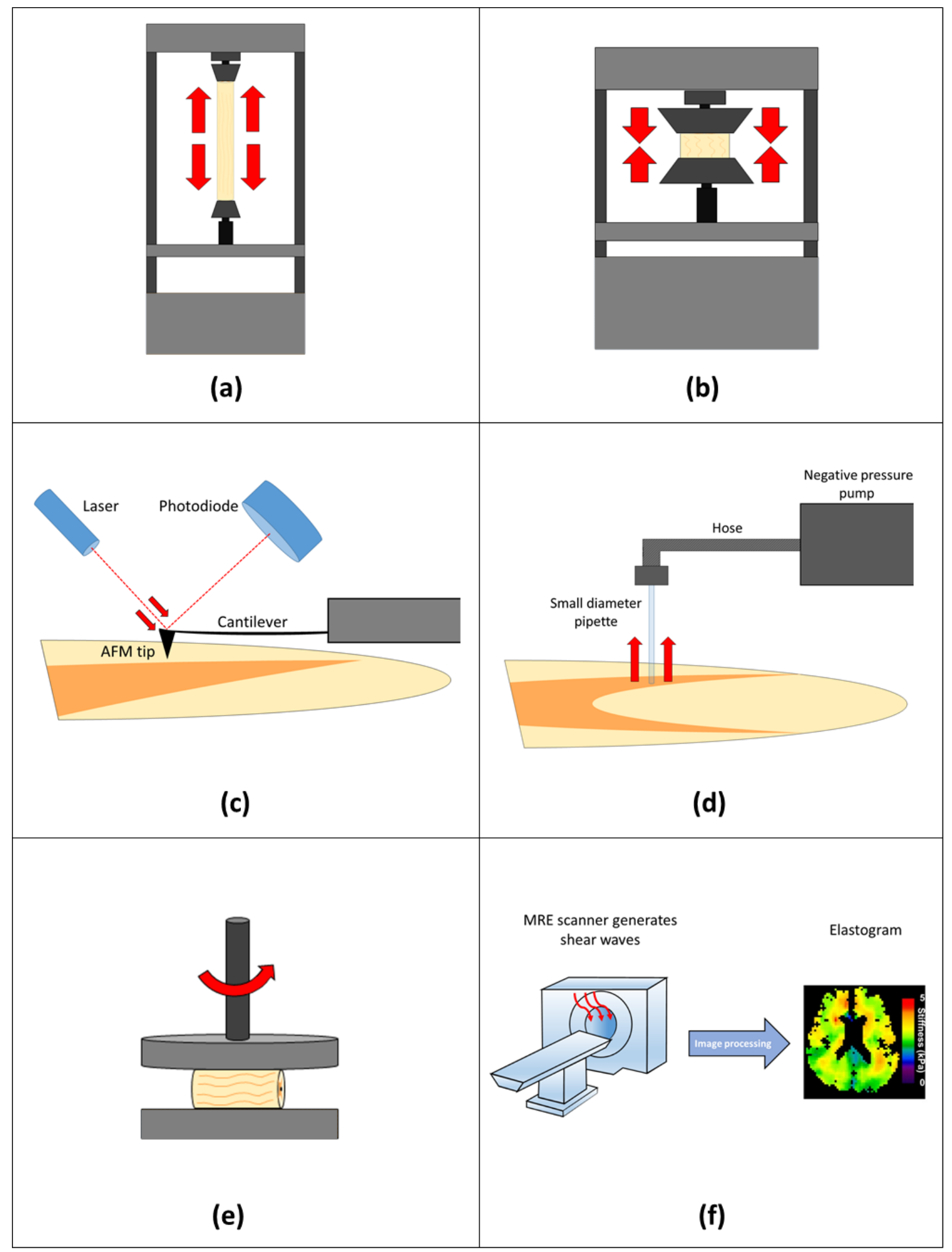

Figure 3. Diagrammatic overview of the main techniques used in the mechanical testing of CNS tissue. a) Uniaxial tensile testing [20-28], b) Uniaxial compression testing [29-32, 112], c) Atomic force microscopy [33, 34], d) Pipette aspiration [38], e) Rheometry [64-66], f) Magnetic resonance electrography [58-60, 83, 86]. Note: beige substrate represents spinal cord tissue; red arrows depict applied forces. Brain elastogram image in e) reproduced with permission from Murphy et al.

[113]. 


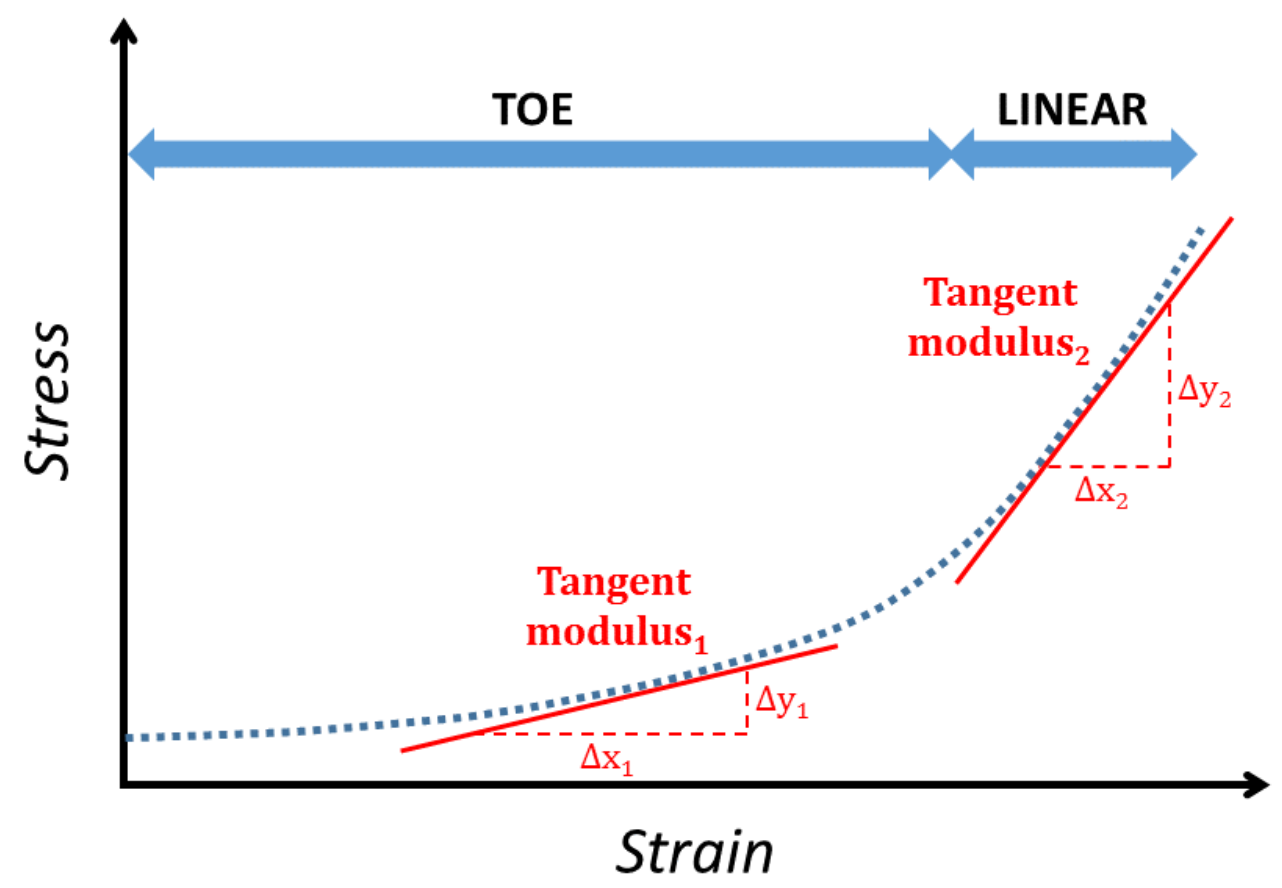

Figure 2. Schematic graph showing the typical load-deformation characteristics of spinal cord tissue in mechanical testing. Blue arrows depict two distinct regions of non-linear behaviour: toe deformation and linear deformation. Solid red lines represent how tangent modulus values might be calculated as a function of the stress-strain relationship at different strains [25].

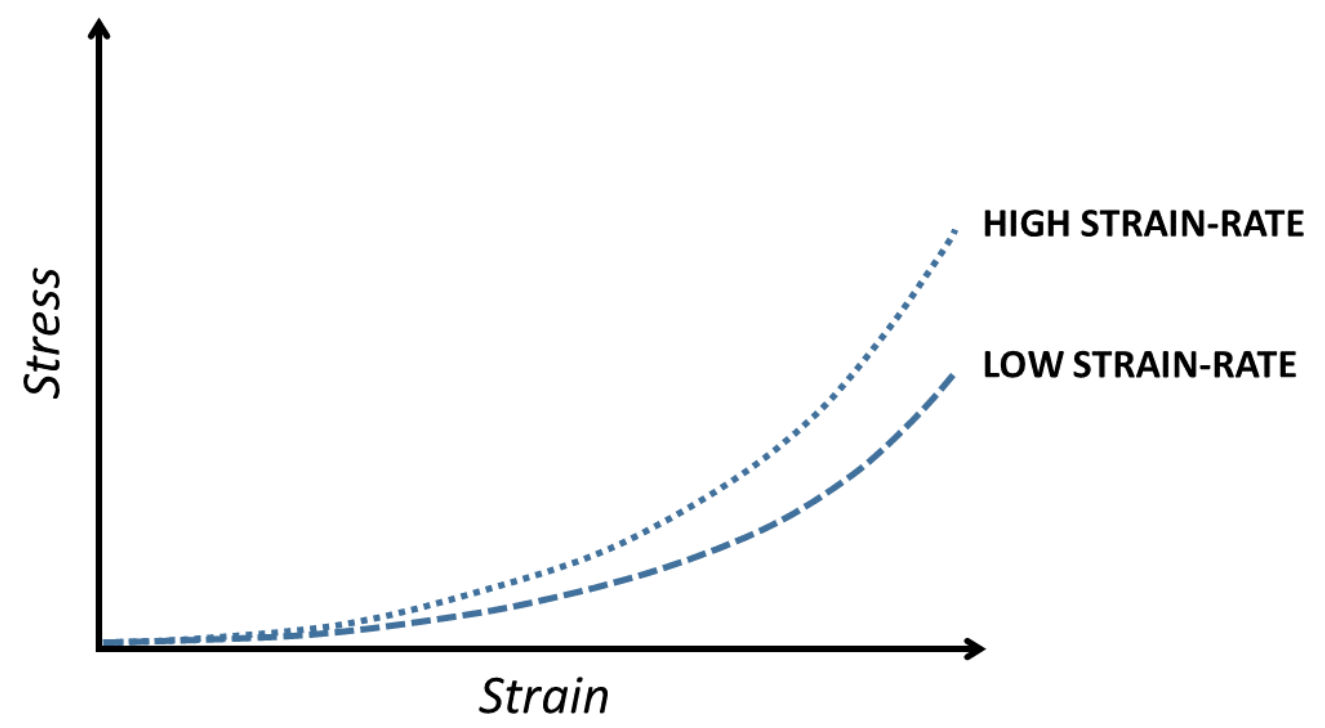

Figure 3. Schematic graph depicting how the viscoelastic properties of spinal cord tissue mean that the overall stress is dependent not only on strain but also on strain-rate $[20,22]$. 


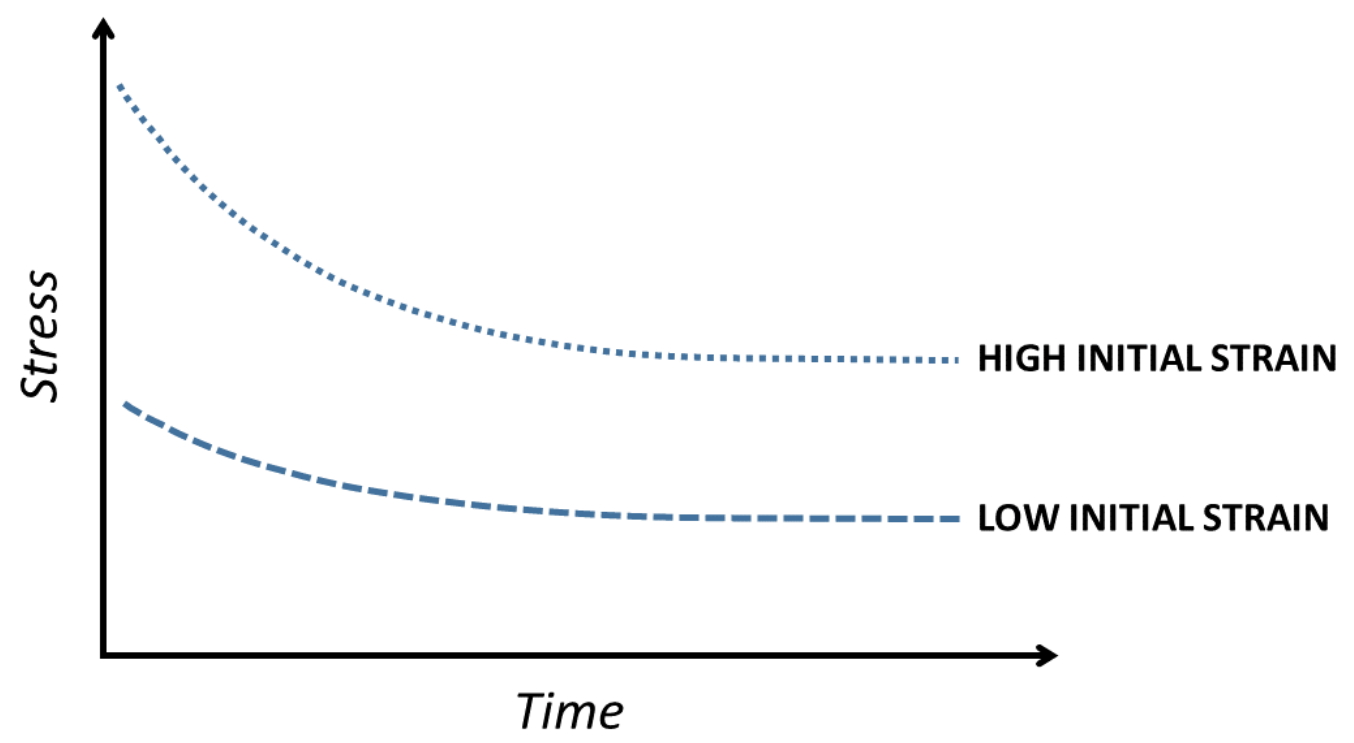

Figure 4. Graph depicting how stress-relaxation time might be an important consideration when measuring spinal cord tissue immediately after handling. Stress can be seen to decay exponentially as a function of time and also seen to vary depending on the magnitude of initial loading strain applied [22].

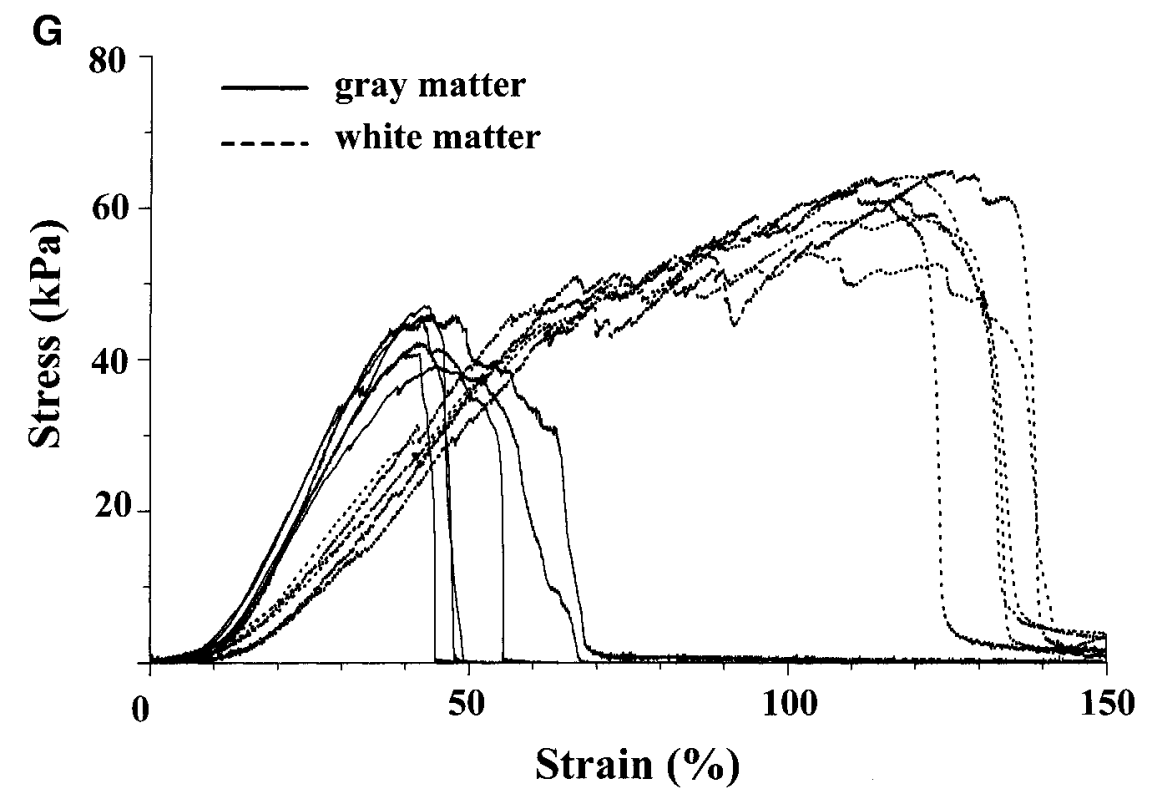

Figure 5. Graph comparing the deformation characteristics of grey and white matter in the cervical bovine spinal cord under compression. Results suggest that although for high strain deformation there are substantial differences between the moduli of grey and white matter, at lower strains the mechanical properties of the two tissue sub-types may be largely similar. Reproduced from Ichihara et al. [23]. 


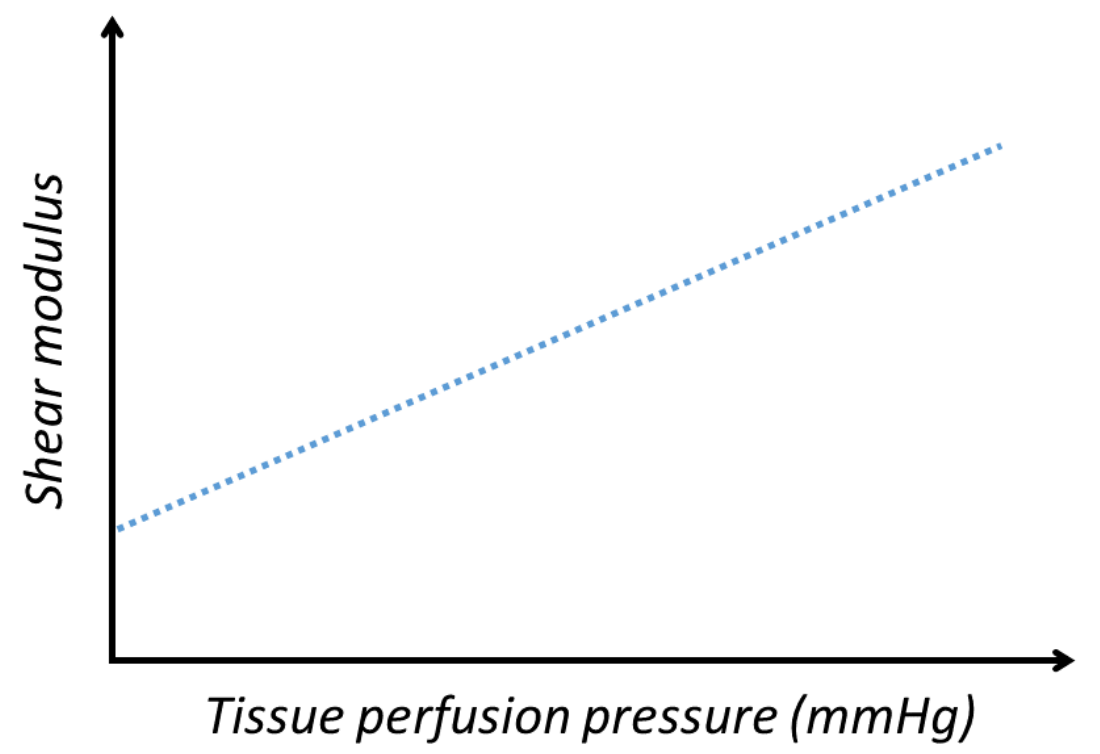

Figure 6. Schematic graph displaying the linear relationship between shear modulus and tissue perfusion pressure in brain tissue [86].

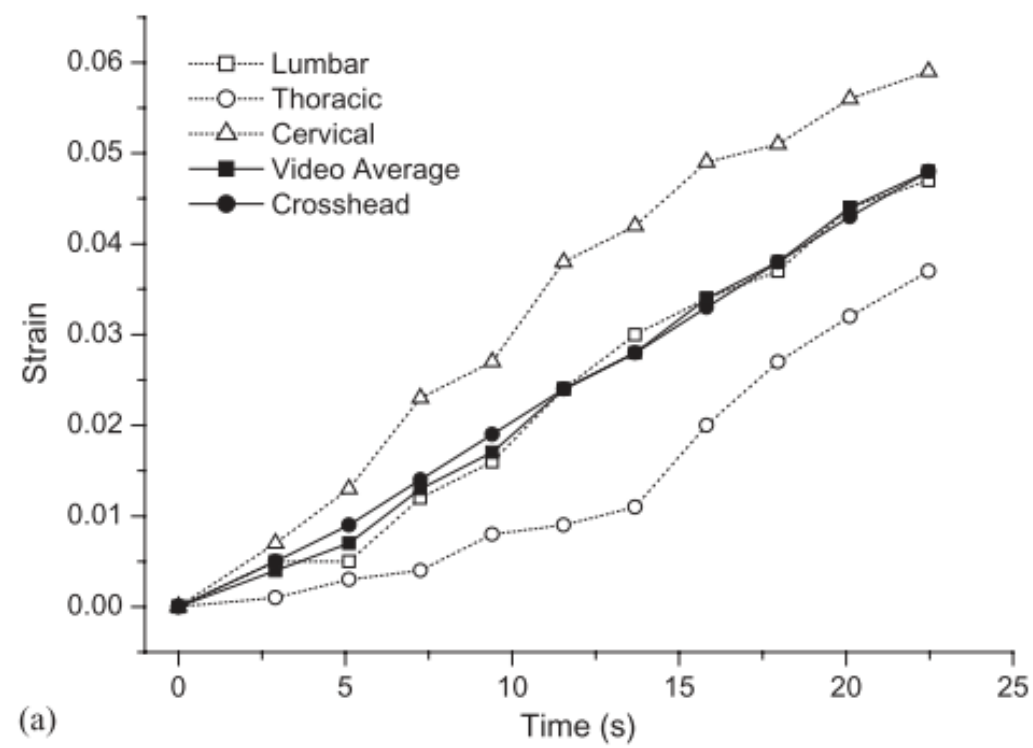

Figure 7. Representation of how rostro-caudal location within the cord might affect local stress-relaxation time. Reproduced from Fiford et al. [22] 


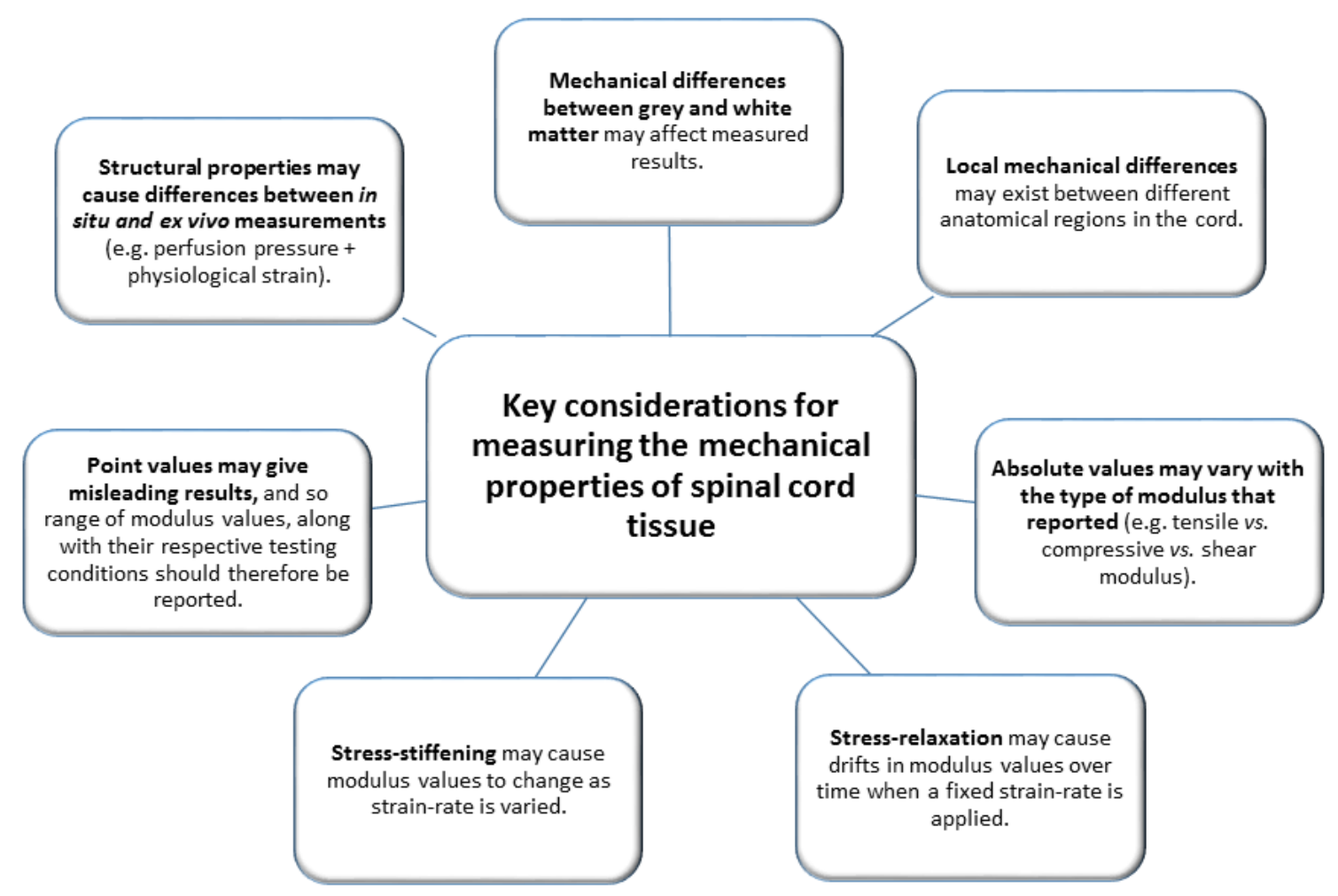

Figure 8. Summary of considerations for mechanical testing approaches. Ultimately, each mechanical measurement technique offers a trade-off of unique advantages and disadvantages in the measurement of spinal cord tissue. These must be considered in the context of the specific research question which is trying to be addressed, and no single measurement technique is likely to overcome all these of the challenges associated with the robust measurement of viscoelastic spinal cord tissue. 


\section{References:}

1. Watson C, Kayalioglu G. Chapter 1 - The Organization of the Spinal Cord. In: The Spinal Cord, Watson C (Ed.^(Eds).Academic Press San Diego 1-7 (2009).

2. Heise C, Kayalioglu G. Chapter 6 - Cytoarchitecture of the Spinal Cord. In: The Spinal Cord, Watson C (Ed.^(Eds).Academic Press San Diego 64-93 (2009).

3. Kayalioglu G. Chapter 3 - The Vertebral Column and Spinal Meninges. In: The Spinal Cord, Watson C (Ed.^(Eds).Academic Press San Diego 17-36 (2009).

4. World Health Organization. Spinal cord injury. (30/09/2015), (2013).

5. Spinal Research. Facts and Figures. (19/12/2013), (2011).

6. Horn SD, Smout RJ, Dejong G et al. Association of Various Comorbidity Measures With Spinal Cord Injury Rehabilitation Outcomes. Archives of Physical Medicine and Rehabilitation 94(4), S75-S86 (2013).

7. National Spinal Injury Statistical Center. Facts and Figures at a Glance. (2015).

8. Beck CW, Christen B, Slack JMW. Molecular pathways needed for regeneration of spinal cord and muscle in a vertebrate. Developmental Cell 5(3), 429-439 (2003).

9. Ferraro GB, Alabed $\mathrm{YZ}$, Fournier AE. Molecular targets to promote central nervous system regeneration. Current Neurovascular Research 1(1), 61-75 (2004).

10. Tessier-Lavigne M. Wiring the brain: the logic and molecular mechanisms of axon guidance and regeneration. Harvey lectures 98 103-143 (2002).

11. Zurn AD, Bandtlow CE. Regeneration failure in the CNS: Cellular and molecular mechanisms. In: Brain Repair, Bahr M 54-76 (2006).

12. Edeleva EV, Shcherbata HR. Stress-induced ECM alteration modulates cellular microRNAs that feedback to readjust the extracellular environment and cell behavior. Frontiers in Genetics 4 305-Article No.: 305 (2013).

13. Engler AJ, Sen S, Sweeney HL, Discher DE. Matrix elasticity directs stem cell lineage specification. Cell 126(4), 677-689 (2006).

14. Wells RG. The role of matrix stiffness in regulating cell behavior. Hepatology 47(4), 13941400 (2008).

15. Hoffman BD, Grashoff C, Schwartz MA. Dynamic molecular processes mediate cellular mechanotransduction. Nature 475(7356), 316-323 (2011).

16. Dufort CC, Paszek MJ, Weaver VM. Balancing forces: architectural control of mechanotransduction. Nature Reviews Molecular Cell Biology 12(5), 308-319 (2011).

17. Wozniak MA, Chen CS. Mechanotransduction in development: a growing role for contractility. Nature Reviews Molecular Cell Biology 10(1), 34-43 (2009).

18. Franze K. The mechanical control of nervous system development. Development 140(15), 3069-3077 (2013).

19. Moshayedi P, Ng G, Kwok JC et al. The relationship between glial cell mechanosensitivity and foreign body reactions in the central nervous system. Biomaterials 35(13), 3919-3925 (2014).

20. Bilston LE, Thibault LE. The mechanical properties of the human cervical spinal cord in vitro. Annals of Biomedical Engineering 24(1), 67-74 (1996).

21. Clarke EC, Cheng S, Bilston LE. The mechanical properties of neonatal rat spinal cord in vitro, and comparisons with adult. Journal of Biomechanics 42(10), 1397-1402 (2009).

22. Fiford RJ, Bilston LE. The mechanical properties of rat spinal cord in vitro. Journal of Biomechanics 38(7), 1509-1515 (2005). 
23. Ichihara K, Taguchi T, Shimada Y, Sakuramoto I, Kawano S, Kawai S. Gray matter of the bovine cervical spinal cord is mechanically more rigid and fragile than the white matter. Journal of Neurotrauma 18(3), 361-367 (2001).

24. Luna C, Detrick L, Shah SB, Cohen AH, Aranda-Espinoza H. Mechanical properties of the lamprey spinal cord: Uniaxial loading and physiological strain. Journal of Biomechanics 46(13), 2194-2200 (2013).

25. Oakland RJ, Hall RM, Wilcox RK, Barton DC. The biomechanical response of spinal cord tissue to uniaxial loading. Proceedings of the Institution of Mechanical Engineers Part H-Journal of Engineering in Medicine 220(H4), 489-492 (2006).

26. Shreiber DI, Hao H, Elias Ral. Probing the influence of myelin and glia on the tensile properties of the spinal cord. Biomechanics and Modeling in Mechanobiology 8(4), 311-321 (2009).

27. Miller K, Chinzei K. Mechanical properties of brain tissue in tension. Journal of Biomechanics 35(4), 483-490 (2002).

28. Tunturi AR. Elasticity of spinal-cord, pia, and denticulate ligament in dog. Journal of Neurosurgery 48(6), 975-979 (1978).

29. Carlson GD, Warden KE, Barbeau JM et al. Viscoelastic relaxation and regional blood flow response to spinal cord compression and decompression. Spine 22(12), 1285-1291 (1997).

30. Hung TK, Lin HS, Bunegin L, Albin MS. Mechanical and neurological response of cat spinalcord under static loading. Surgical Neurology 17(3), 213-217 (1982).

31. Prevost TP, Balakrishnan A, Suresh S, Socrate S. Biomechanics of brain tissue. Acta Biomaterialia 7(1), 83-95 (2011).

32. Sparrey CJ, Keaveny TM. Compression behavior of porcine spinal cord white matter. Journal of Biomechanics 44(6), 1078-1082 (2011).

33. Christ AF, Franze K, Gautier H et al. Mechanical difference between white and gray matter in the rat cerebellum measured by scanning force microscopy. Journal of Biomechanics 43(15), 2986-2992 (2010).

34. Koser DE, Moeendarbary E, Hanne J, Kuerten S, Franze K. CNS Cell Distribution and Axon Orientation Determine Local Spinal Cord Mechanical Properties. Biophysical Journal 108(9), 2137-2147 (2015).

35. Nanoscience Instruments. AFM Probes. (11/11/2015), (2015).

36. Jalili $\mathrm{N}$, Laxminarayana K. A review of atomic force microscopy imaging systems: application to molecular metrology and biological sciences. Mechatronics 14(8), 907-945 (2004).

37. Yongho S, Wonho J. Atomic force microscopy and spectroscopy. Reports on Progress in Physics 71(1), 016101 (2008).

38. Ozawa H, Matsumoto T, Ohashi T, Sato M, Kokubun S. Comparison of spinal cord ray matter and white matter softness: measurement by pipette aspiration method. Journal of Neurosurgery 95(2), 221-224 (2001).

39. Cheng S, Clarke EC, Bilston LE. Rheological properties of the tissues of the central nervous system: A review. Medical Engineering \& Physics 30(10), 1318-1337 (2008).

40. Fallenst GT, Hulce VD, Melvin JW. Dynamic Mechanical Properties of Human Brain Tissue. Journal of Biomechanics 2(3), 217-\& (1969).

41. Bilston LE, Liu ZZ, Phan-Thien N. Large strain behaviour of brain tissue in shear: Some experimental data and differential constitutive model. Biorheology 38(4), 335-345 (2001).

42. Cheng S, Clarke EC, Bilston LE. The effects of preconditioning strain on measured tissue properties. J Biomech 42(9), 1360-1362 (2009).

43. Bilston LE, Liu ZZ, Nhan PT. Linear viscoelastic properties of bovine brain tissue in smear. Biorheology 34(6), 377-385 (1997).

44. Quinn KP, Winkelstein BA. Preconditioning is correlated with altered collagen fiber alignment in ligament. J Biomech Eng 133(6), 064506 (2011). 
45. Hosseini SM, Wilson W, Ito K, Van Donkelaar CC. How preconditioning affects the measurement of poro-viscoelastic mechanical properties in biological tissues. Biomechanics and Modeling in Mechanobiology 13(3), 503-513 (2014).

46. Rashid B, Destrade M, Gilchrist MD. Influence of preservation temperature on the measured mechanical properties of brain tissue. Journal of Biomechanics 46(7), 1276-1281 (2013).

47. Oakland RJ, Hall RM, Wilcox RK, Barton DC. The biomechanical response of spinal cord tissue to uniaxial loading. Proc Inst Mech Eng H 220(4), 489-492 (2006).

48. Clarke EC, Cheng S, Bilston LE. The mechanical properties of neonatal rat spinal cord in vitro, and comparisons with adult. J Biomech 42(10), 1397-1402 (2009).

49. Ichihara K, Taguchi T, Shimada Y, Sakuramoto I, Kawano S, Kawai S. Gray matter of the bovine cervical spinal cord is mechanically more rigid and fragile than the white matter. $J$ Neurotrauma 18(3), 361-367 (2001).

50. Mckee CT, Last JA, Russell P, Murphy CJ. Indentation Versus Tensile Measurements of Young's Modulus for Soft Biological Tissues. Tissue Engineering Part B-Reviews 17(3), 155164 (2011).

51. Metz H, Mcelhane J, Ommaya AK. A comparison of elasticity of live, dead, and fixed brain tissue. Journal of Biomechanics 3(4), 453-\& (1970).

52. Tetzlaff W, Okon EB, Karimi-Abdolrezaee $\mathrm{S}$ et al. A Systematic Review of Cellular Transplantation Therapies for Spinal Cord Injury. Journal of Neurotrauma 28(8), 1611-1682 (2011).

53. Litwiller DV, Mariappan YK, Ehman RL. Magnetic Resonance Elastography. Current Medical Imaging Reviews 8(1), 46-55 (2012).

54. Mariappan YK, Glaser KJ, Ehman RL. Magnetic Resonance Elastography: A Review. Clinical Anatomy 23(5), 497-511 (2010).

55. Liu G-R, Gao P-Y, Lin Y et al. Brain Magnetic Resonance Elastography on Healthy Volunteers: A Safety Study. Acta Radiologica 50(4), 423-429 (2009).

56. Ehman EC, Rossman PJ, Kruse SA, Sahakian AV, Glaser KJ. Vibration safety limits for magnetic resonance elastography. Physics in medicine and biology 53(4), 925-935 (2008).

57. Singh S, Venkatesh SK, Wang Z et al. Diagnostic Performance of Magnetic Resonance Elastography in Staging Liver Fibrosis: A Systematic Review and Meta-analysis of Individual Participant Data. Clinical Gastroenterology and Hepatology 13(3), 440-451.e446 (2015).

58. Green MA, Bilston LE, Sinkus R. In vivo brain viscoelastic properties measured by magnetic resonance elastography. Nmr in Biomedicine 21(7), 755-764 (2008).

59. Kruse SA, Rose GH, Glaser KJ et al. Magnetic resonance elastography of the brain. Neuroimage 39(1), 231-237 (2008).

60. Sack I, Beierbach B, Hamhaber U, Klatt D, Braun J. Non-invasive measurement of brain viscoelasticity using magnetic resonance elastography. Nmr in Biomedicine 21(3), 265-271 (2008).

61. Schwarb H, Johnson CL, Mcgarry MD, Cohen NJ. Medial temporal lobe viscoelasticity and relational memory performance. Neuroimage 132 534-541 (2016).

62. Anderson AT, Van Houten EE, Mcgarry MD et al. Observation of direction-dependent mechanical properties in the human brain with multi-excitation MR elastography. J Mech Behav Biomed Mater 59 538-546 (2016).

63. Kruse S, Kolipaka A, Manduca A, Ehman R. Feasibility of Evaluating the Spinal Cord with MR Elastography. Presented at: 17th Scientific Meeting, International Society for Magnetic Resonance in Medicine. Honolulu 2009.

64. Bilston LE, Liu Z, Phan-Thien N. Linear viscoelastic properties of bovine brain tissue in shear. Biorheology 34(6), 377-385 (1997).

65. Li G, Zhang J, Wang K, Wang M, Gao C, Ma C. Experimental research of mechanical behavior of porcine brain tissue under rotational shear stress. J Mech Behav Biomed Mater 57 224234 (2016). 
66. Nicolle S, Lounis M, Willinger R, Palierne JF. Shear linear behavior of brain tissue over a large frequency range. Biorheology 42(3), 209-223 (2005).

67. Franze K, Janmey PA, Guck J. Mechanics in neuronal development and repair. Annu Rev Biomed Eng 15 227-251 (2013).

68. The Open University. Introduction to polymers - elastic and viscoelastic behaviours. (2015).

69. Mihai LA, Chin L, Janmey PA, Goriely A. A comparison of hyperelastic constitutive models applicable to brain and fat tissues. J R Soc Interface 12(110), 0486 (2015).

70. Chang CT, Chen YH, Lin CC, Ju MS. Finite element modeling of hyper-viscoelasticity of peripheral nerve ultrastructures. J Biomech 48(10), 1982-1987 (2015).

71. Roylance D. Engineering Viscoelasticity. (2001).

72. Bechir $\mathrm{H}$, Idjeri $\mathrm{M}$. Computation of the relaxation and creep functions of elastomers from harmonic shear modulus. Mechanics of Time-Dependent Materials 15(2), 119-138 (2011).

73. Xu J, Ju Y, Han B, Zhou C, Zheng J. Research on relaxation modulus of viscoelastic materials under unsteady temperature states based on TTSP. Mechanics of Time-Dependent Materials 17(4), 543-556 (2013).

74. Budday S, Nay R, De Rooij R et al. Mechanical properties of gray and white matter brain tissue by indentation. J Mech Behav Biomed Mater 46 318-330 (2015).

75. Mccracken PJ, Manduca A, Felmlee J, Ehman RL. Mechanical transient-based magnetic resonance elastography. Magn Reson Med 53(3), 628-639 (2005).

76. Uffmann K, Maderwald S, De Greiff A, Ladd M. Determination of Gray and White Matter Elasticity with MR Elastography. International Society for Magnetic Resonance in Medicine (2004).

77. Zhang J, Green MA, Sinkus R, Bilston LE. Viscoelastic properties of human cerebellum using magnetic resonance elastography. J Biomech 44(10), 1909-1913 (2011).

78. Feng Y, Clayton EH, Chang Y, Okamoto RJ, Bayly PV. Viscoelastic properties of the ferret brain measured in vivo at multiple frequencies by magnetic resonance elastography. Journal of Biomechanics 46(5), 863-870 (2013).

79. Hamhaber U, Sack I, Papazoglou S, Rump J, Klatt D, Braun J. Three-dimensional analysis of shear wave propagation observed by in vivo magnetic resonance elastography of the brain. Acta Biomaterialia 3(1), 127-137 (2007).

80. Mamata $\mathrm{H}$, Jolesz FA, Maier SE. Characterization of central nervous system structures by magnetic resonance diffusion anisotropy. Neurochem Int 45(4), 553-560 (2004).

81. Carlsen RW, Daphalapurkar NP. The importance of structural anisotropy in computational models of traumatic brain injury. Frontiers in neurology 6 28-28 (2015).

82. Kong Y, Shi L, Hui SCN et al. Variation in Anisotropy and Diffusivity along the Medulla Oblongata and the Whole Spinal Cord in Adolescent Idiopathic Scoliosis: A Pilot Study Using Diffusion Tensor Imaging. American Journal of Neuroradiology 35(8), 1621-1627 (2014).

83. Arani A, Murphy MC, Glaser KJ et al. Measuring the effects of aging and sex on regional brain stiffness with MR elastography in healthy older adults. Neuroimage 111 59-64 (2015).

84. Maneshi MM, Sachs F, Hua SZ. A Threshold Shear Force for Calcium Influx in an Astrocyte Model of Traumatic Brain Injury. Journal of neurotrauma 32(13), 1020-1029 (2015).

85. Budday S, Steinmann P, Kuhl E. Physical biology of human brain development. Frontiers in Cellular Neuroscience 9257 (2015).

86. Weavee JB, Perrinez PR, Bergeron JA et al. The effects of interstitial tissue pressure on the measured shear modulus in vivo - art. no. 65111A. In: Medical Imaging 2007: Physiology, Function, and Structure from Medical Images, Manduca A,Hu XP A5111-A5111 (2007).

87. Etz CD, Di Luozzo G, Zoli S et al. Direct spinal cord perfusion pressure monitoring in extensive distal aortic aneurysm repair. Ann Thorac Surg 87(6), 1764-1773; discussion 1773-1764 (2009).

88. Dunn LT. Raised intracranial pressure. Journal of Neurology Neurosurgery and Psychiatry 73 123-127 (2002). 
89. Raghavan M, Sahar ND, Kohn DH, Morris MD. Age-specific profiles of tissue-level composition and mechanical properties in murine cortical bone. Bone 50(4), 942-953 (2012).

90. Chantereau P, Brieu M, Kammal M, Farthmann J, Gabriel B, Cosson M. Mechanical properties of pelvic soft tissue of young women and impact of aging. International Urogynecology Journal 25(11), 1547-1553 (2014).

91. Hasson CJ, Caldwell GE. Effects of Age on Mechanical Properties of Dorsiflexor and Plantarflexor Muscles. Annals of Biomedical Engineering 40(5), 1088-1101 (2012).

92. Elkin BS, Ilankovan A, Morrison B, 3rd. Age-dependent regional mechanical properties of the rat hippocampus and cortex. J Biomech Eng 132(1), 011010 (2010).

93. Christ AF, Franze K, Gautier H et al. Mechanical difference between white and gray matter in the rat cerebellum measured by scanning force microscopy. J Biomech 43(15), 2986-2992 (2010).

94. Green MA, Bilston LE, Sinkus R. In vivo brain viscoelastic properties measured by magnetic resonance elastography. NMR Biomed 21(7), 755-764 (2008).

95. Johnson CL, Mcgarry MDJ, Van Houten EEW et al. Magnetic Resonance Elastography of the Brain using Multi-Shot Spiral Readouts with Self-Navigated Motion Correction. Magnetic resonance in medicine : official journal of the Society of Magnetic Resonance in Medicine / Society of Magnetic Resonance in Medicine 70(2), 404-412 (2013).

96. Ugurbil $\mathrm{K}, \mathrm{Xu}$ J, Auerbach EJ et al. Pushing spatial and temporal resolution for functional and diffusion MRI in the Human Connectome Project. Neuroimage 80 80-104 (2013).

97. Perkin Elmer Inc. Frequently Asked Questions: Dynamic Mechanical Analysis (DMA). doi:007993A_01 (2013).

98. Scull ER. Dynamic mechanical response characteristics of spinal-cord tisssue - preliminary report. Paraplegia 17(2), 222-232 (1979).

99. Ruiter GCWD, Malessy MJA, Yaszemski MJ, Windebank AJ, Spinner RJ. Designing ideal conduits for peripheral nerve repair. Neurosurgical Focus 26(2), (2009).

100. Cheng C, Kmech J, Mushahwar VK, Elias AL. Development of Surrogate Spinal Cords for the Evaluation of Electrode Arrays Used in Intraspinal Implants. Transactions on Biomedical Engineering 60(6), 1667-1676 (2013).

101. Jerusalem A, Garcia-Grajales JA, Merchan-Perez A, Pena JM. A computational model coupling mechanics and electrophysiology in spinal cord injury. Biomechanics and Modeling in Mechanobiology 13(4), 883-896 (2014).

102. Sakuramoto I, Ichihara K, Ohgi J, Chen X, Kawano S, Taguchi T. Mechanical properties of the white and gray matter in the spinal cord at high strain rates for computer simulation model of the spinal cord injury. Society for Neuroscience Abstract Viewer and Itinerary Planner 42 (2012).

103. Elkin BS, Morrison B, lii, Asme. Mechanical properties of the rat brain: effect of age and anatomical region. (2010).

104. Flanagan LA, Ju YE, Marg B, Osterfield M, Janmey PA. Neurite branching on deformable substrates. Neuroreport 13(18), 2411-2415 (2002).

105. Georges PC, Miller WJ, Meaney DF, Sawyer ES, Janmey PA. Matrices with Compliance Comparable to that of Brain Tissue Select Neuronal over Glial Growth in Mixed Cortical Cultures. Biophysical Journal 90(8), 3012-3018 (2006).

106. Lukovic D, Stojkovic M, Moreno-Manzano V et al. Concise Review: Reactive Astrocytes and Stem Cells in Spinal Cord Injury: Good Guys or Bad Guys? STEM CELLS 33(4), 1036-1041 (2015).

107. Spinal Cord Injury Facts and Figures at a Glance. The Journal of Spinal Cord Medicine 35(4), 197-198 (2012).

108. Lukovic D, Stojkovic M, Moreno-Manzano V et al. Concise review: reactive astrocytes and stem cells in spinal cord injury: good guys or bad guys? Stem Cells 33(4), 1036-1041 (2015). 
109. Raspa A, Pugliese R, Maleki M, Gelain F. Recent therapeutic approaches for spinal cord injury. Biotechnol Bioeng 113(2), 253-259 (2016).

110. Boulet T, Kelso ML, Othman SF. Microscopic magnetic resonance elastography of traumatic brain injury model. Journal of Neuroscience Methods 201(2), 296-306 (2011).

111. European Commission. EudraLex - Volume 4 Good manufacturing practice (GMP) Guidelines. (2015).

112. Cheng S, Bilston LE. Unconfined compression of white matter. Journal of Biomechanics 40(1), 117-124 (2007).

113. Murphy MC, Huston J, lii, Jack CR, Jr. et al. Measuring the Characteristic Topography of Brain Stiffness with Magnetic Resonance Elastography. Plos One 8(12), (2013). 